\title{
\$sciendo
}

DOI 10.2478/afepuc-2020-0019

(C) Acta Facultatis Educationis Physicae Universitatis Comenianae 2020, 60(2): 229-240

\section{TYPES OF CLASSROOM CHAIR STRETCH EXERCISES AND THEIR FEASIBILITY AND POTENTIAL TO STRUCTURE THE RECOMMEND CLASSROOM-BASED PHYSICAL ACTIVITY BREAK PRIMARY PROGRAMS}

\author{
Mohamed Arab Kerroum, Mohammed Zerf
}

Institute of Physical Education and Sports, University Abdel Hamid Ibn Badis, Mostaganem, Algeria

\begin{abstract}
Summary: This pilot study tests the significance of a classroom chair stretch exercises types and their feasibility and potential to structure the optional classrooms Based Physical Activity Break Primary Programs (ABC-PA). Materials and methods. To achieve this goal, we proposed two chair stretch exercises ABC-PA programs, one with sit-to-stand chair exercises and other without sit-to-stand chair exercises. Applied for 4-weeks among 90 children, five grade levels, 45 in each division during the academic years 2017-2018. Controlled by components of Fitness Gram health-related physical fitness, before and after 4-weeks of the research project to establish the superiority of the two models proposed. Results. To admit study ABC-PA protocols, and statistics performed. Our outcomes confirmed sit-tostand as the recommended exercise to structure the optional classroom-based physical activity breaks routine intervention. Conclusions. We approved the sit-to-stand as a powerful chair exercise able to enhance cardiovascular endurance, muscle strength, muscular endurance, flexibility, maintenance of body composition and reduction of prolonged class daily time sittings. More efficacy are the sit-downs noticed in this study as prolonged static stretch able to improve static flexibility but without changes in classrooms sedentary routine .
\end{abstract}

Keywords: classroom, children, chair exercise, breaks based physical activity intervention,

\section{Introduction}

Research indicates that prolonged sitting daily classroom is sedentary behaviour with defective biological consequences associated with chronic extended periods of muscular limbs inactivity (Mohammed 2018). Authenticated by population health-based studies as one of the several significant public health problems within the 21 st century (Izet 2018). At significantly 
elevated risk for the decrease of energy consumption of the musculoskeletal system amounts of multi-joint immobility. Comment by Farzane et al. (2018) in the case of the workplace via the replacement of sitting by standing as one of several recommendations to reduce sedentary time and increase everyday energy expenditure to control weight gain in the long term (Farzane et al. 2018). Estimated by Uraiwan et al. (2015) to be done after every 2-hour of prolonged sittings. The opposite of physical medicine and rehabilitation studies that recommended its employment to be done after every 20 or 30 minutes long sitting. Break programs studies as real healthrelated fitness guidelines command to avoid physical inactivity costs of $(6-8 \mathrm{~h})$ lengthened sit-in classrooms daily hours (Virginia et al. 2016). Recently, pilot trial primary school studies challenged within classroom routine teachers to include sit-stand desks or 5 min bursts break of moderate-intensity physical activity per day (Amanda et al. 2017). It was pointed as exemplary strategies for routine classroom conditions leading to the recommended healthrelated fitness (Chin et al. 2012).

Australian teachers advised through classroom interventions, no longer than $5 \mathrm{~min}$ and without interspace or set-up in the classroom, according to (Agata et al. 2018). Practices used by Algerians primary school teachers through sit-downs were shown as ideal class guidelines aspects of respectable teaching discipline and successful learning behaviour, according to Mohammed et al. 2017.

To support the above teachers' recommendations as complexities this strategy should be integrated into the daily routine class schools. The contrary of work conditions studies commanding dynamic sitting as optional practice being used to help people moving more at the workplace (Koepp et al. 2016). Amanda et al. (2019) claimed minor changes in terms of frequency and intensity to improve classroom Based Physical Activity Break Programs. Encouraging future research to address these issues (Agata et al. 2018). The case of this experimental study was focused testing the significance of the stretch chair exercises types on the efficacy of classrooms Based Physical Activity Break Primary Programs. It was examined by the present study under two approaches with and without a set-up, among 90 children, five grade levels, 45 in each division, during the academic years $(2017-2018)$. Figure 1, 2 as content and Figure 3 show us the time practises and standing at the classroom. Assessed by components of Fitness Gram health-related physical fitness,it was applied before and after 4weeks of the research project to determine the superiority of the two models proposed.

\section{Methods}


This experimental study attends to test the significance of chair-type exercises on the efficacy of classrooms Based Physical Activity Break Primary Programs. Research was done by the following 2 models of ABC-PA: Group with 3 min Sit-downs Static Stretching Chair Exercises (ABC-PA-Sit-Downs) versus Group with 3 min sit-to-stand mixed Chair exercises (ABC-PA-Sit-to-Stand). Examination was done before and after the realisation of two proposed programs with components of Fitness Gram battery tests, as the most comprehensive and informative program that can drive meaningful behaviour change and set up children for a healthy future (Krause et al. 2014). It was applied during four weeks following the recommended classroom video-based physical activities (content and rhyme) planned for each class, including after each hour of classroom lessons. Total time work was 18 min per day and 72 min during the achievement of experience. The particular role of the teachers, who voluntarily accepted to participate in this experience was limited in application of recommended classroom video-based physical activity, because of time applications and the encouragements of their students for decent engagement.

\section{Participants}

The research group participated in the stud were approximately from 10 to 11 years of age $\left(\overline{\mathrm{X}}=10.5, \mathrm{SD}=0.57\right.$, minimum $=10 .{ }^{\prime}$ maximum $\left.=11\right)$. Table 1 . shows general characteristics in the pre-test.

Table 1

General characteristics of the participants in the pre-test according to Fitness Gram test battery

\begin{tabular}{|l|l|l|l|l|l|}
\hline Variables ABC-PA & $\begin{array}{l}\text { Total } \\
\mathbf{n}=\mathbf{9 0}\end{array}$ & $\begin{array}{l}\text { ABC-PA-Sit- } \\
\text { to-Stand }\end{array}$ & $\begin{array}{l}\text { ABC-PA-Sit- } \\
\text { Downs }\end{array}$ & $\mathbf{T}$ & $\mathbf{P} \leq \mathbf{0 . 0 5}$ \\
\hline Age (years) & $10.5 \pm 0.57$ & $10.1 \pm 0.92$ & $10.5 \pm 0.46$ & 0.46 & 0.76 \\
\hline Body height (cm) & $142 \pm 4.22$ & $143.1 \pm 4.09$ & $142.2 \pm 4.27$ & 0.55 & 0.83 \\
\hline Body weight (kg) & $35.44 \pm 3.66$ & $35.48 \pm 4.32$ & $34.9 \pm 0.78$ & 1.02 & 0.75 \\
\hline Male & 40 & 20 & 20 & & \\
\hline Female & 50 & 25 & 25 & & \\
\hline Grade level & All class 5 grade level & $42.45 \pm 4.05$ & $41.25 \pm 3.92$ & 1.22 & 0.71 \\
\hline Aerobic capacity & $41.28 \pm 4.66$ & $21.88 \pm 2.45$ & $22.23 \pm 1.85$ & 1.47 & 0.44 \\
\hline Body composition & $22.55 \pm 1.55$ & $2.44 \pm 3.42$ & $2.84 \pm 2.52$ & 0.88 & 0.45 \\
\hline $\begin{array}{l}\text { Muscular strength } \\
\text { upper }\end{array}$ & $2.42 \pm 2.35$ & $12.41 \pm 3.02$ & $11.74 \pm 2.52$ & 1.22 & 0.56 \\
\hline $\begin{array}{l}\text { Muscular strength } \\
\text { lower body }\end{array}$ & $11.22 \pm 2.55$ & $7.89 \pm 2.98$ & $8.22 \pm 5.45$ & 0.98 & 0.64 \\
\hline $\begin{array}{l}\text { Endurance } \\
\text { Abdominals }\end{array}$ & $8.88 \pm 3.33$ & $13.99 \pm 2.78$ & $14.37 \pm 4.88$ & 0.42 & 0.58 \\
\hline $\begin{array}{l}\text { flexibility lower back } \\
\text { and hamstring } \\
\text { muscles }\end{array}$ & $14.55 \pm 2.58$ & 25 & & \\
\hline
\end{tabular}


ABC-PA-Sit-Downs: Group with 3 min ABC-PA with static stretching chair exercises/ ABC-PASit-to-Stand Groups with 3 min ABC-PA with Sit-to-Stand mixed dynamic exercises separated by static stretching exercise.

The test battery consisted of Fitness Gram identified as an essential battery to assess three general components of health-related physical fitness (Cooper Institute for Aerobics Research, 2017).

- Aerobic capacity: based on a reduced Cooper test. The child run or walks around a marked rectangle measuring $9 \times 18 \mathrm{~m}$ (the size of a volleyball field) for 6 minutes. Both running and walking are allowed. The test item score is the distance covered in 6 minutes (measured in meters).

- Body composition: based on Body mass index (calculated from height and weight).

- Muscular strength upper and lower body, abdominal endurance, and trunk flexibility:

$\checkmark$ Muscular strength of upper body: based on pushing a medicine ball (1 kg) with two hands as far as possible. The starting position is with the feet parallel to each other and shoulder-width apart, with the ball held against the chest. The test item score (better of two attempts) is the distance achieved (measured in meters).

$\checkmark$ Muscular strength of lower body: based on Vertical Jump Test the student high wall, such as the outside of a building and leaps vertically as high as possible using both arms and legs to assist in projecting the body upwards.

$\checkmark$ Flexibility: based on sit and reach test as the common measure of flexibility and accurately measures the flexibility of the lower back and hamstring muscles. The score is recorded to the nearest centimetre or half inch as the distance reached by the hand.

$\checkmark$ Abdominal endurance: we based on Abdominal Curl-Sit Up endurance tests usually conducted over one minute and measure the maximum number of correctly performed sit-ups in that time.

Children were tested individually. Each test item was explained and demonstrated before the child started. Tested before and after the realisation of the program applied under video sequences, sit in Figures 1 and 2 as content and Figure 3 as time practised. For the progress of students, based on one more repetition for each exercise per week. 

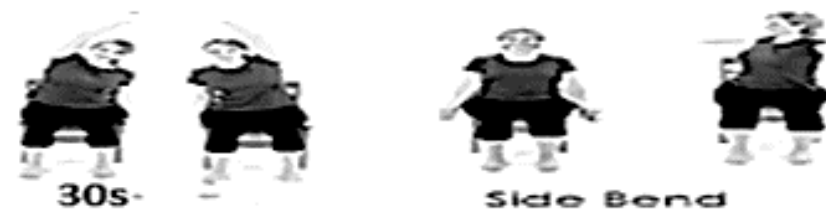

30s
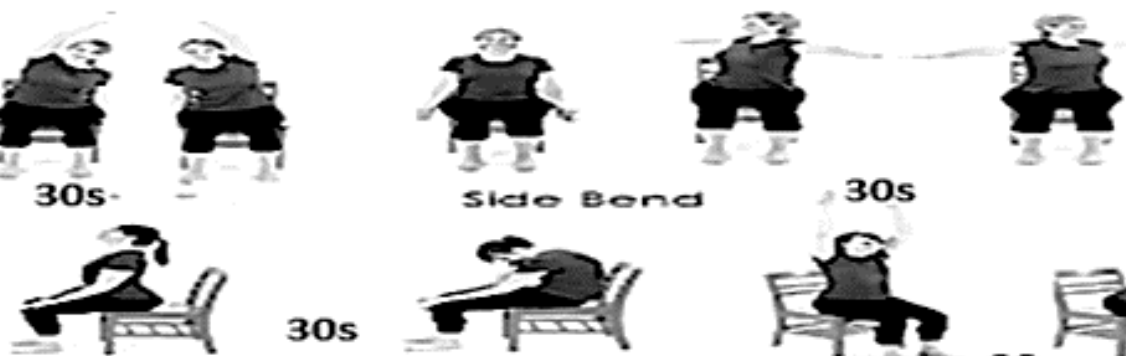

30s
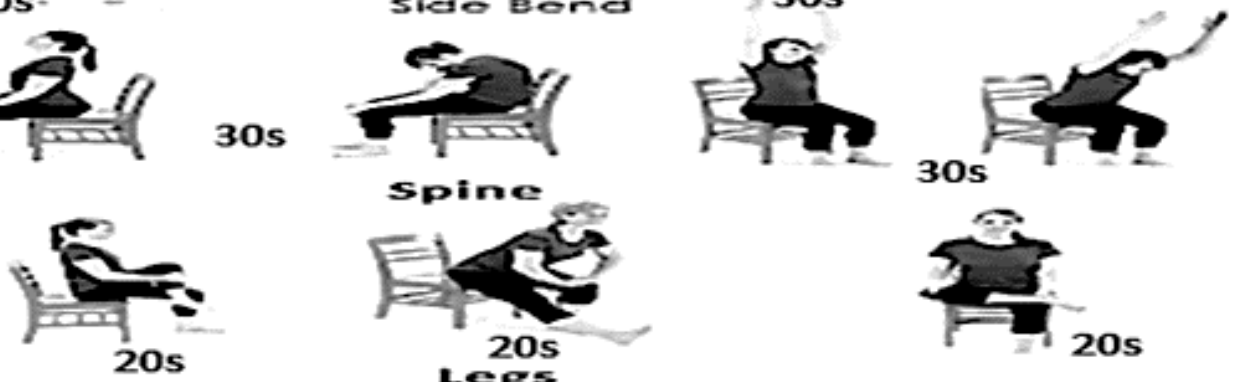

$$
\text { spine }
$$

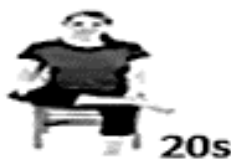

Figure 1

Present the ABC-PA-Sit-Downs

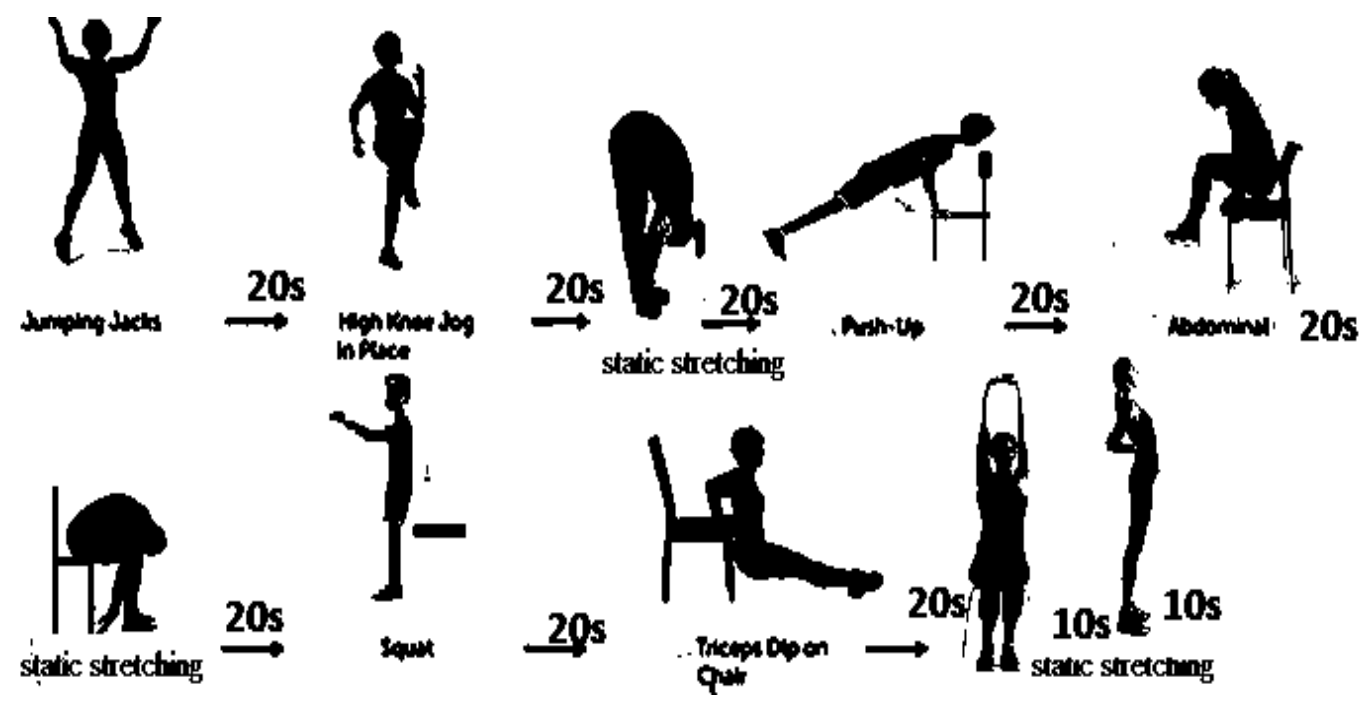

Figure 2

Present the ABC-PA-Sit-to-Stand

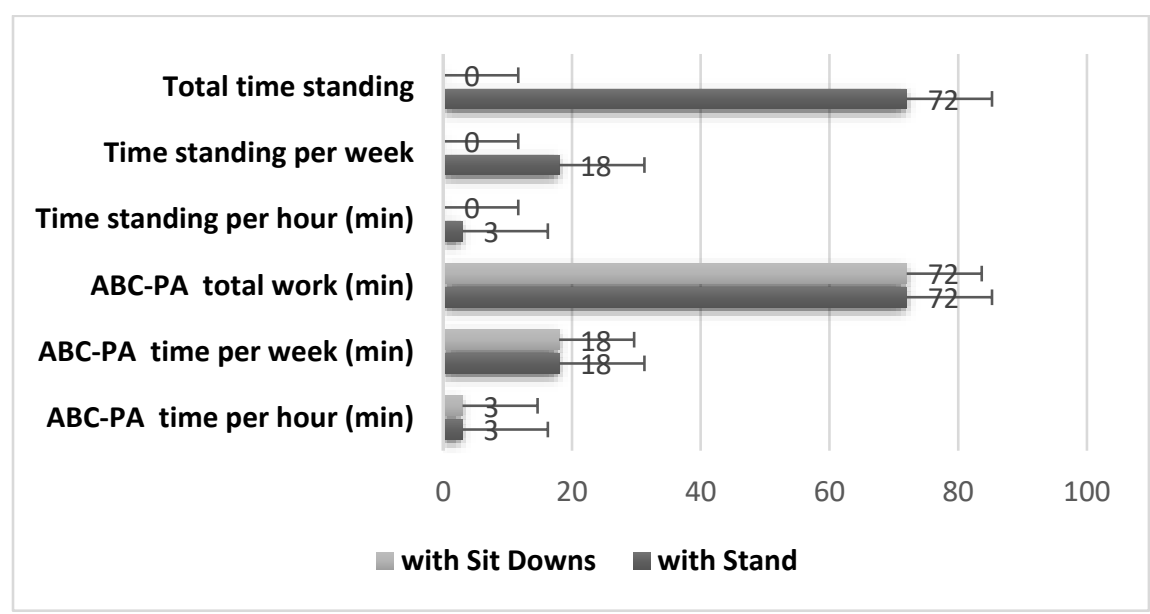

Figure 3

Present the ABC-PA time practises and their differences in time standing desks 
All statistical analyses were performed with SPSS, version 16.0.1, * and consisted of Pearson correlation, and the independent T-test, set at p-value 0.05 .

\section{Results}

Our samples are homogeneous in all pre-test practised, set in Table 1. , confirmed by the insignificance of independent T-test. The opposite of post-test, where all results are in the benefits of model 3 min ABC-PA-Sit-to-Stand, listed in Table 2.

Table 2

Present the post-test health-related fitness component results of samples in the FitnessGram test battery

\begin{tabular}{|l|l|l|l|l|}
\hline Variables & $\begin{array}{l}\text { ABC-PA-Sit-to- } \\
\text { Stand }\end{array}$ & $\begin{array}{l}\text { ABC-PA-Sit- } \\
\text { Downs }\end{array}$ & T & P $\leq \mathbf{0 . 0 5}$ \\
\hline Aerobic capacity & $43.68 \pm 2.08$ & $42.69 \pm 1.12$ & 3.55 & 0.00 \\
\hline Body composition & $21.22 \pm 0.88$ & $22.08 \pm 0.44$ & 2.22 & 0.02 \\
\hline Muscular strength upper body & $3.02 \pm 1.75$ & $2.52 \pm 1.66$ & 2.92 & 0.00 \\
\hline Muscular strength lower body & $17.75 \pm 2.43$ & $13.02 \pm 1.22$ & 4.89 & 0.00 \\
\hline Endurance Abdominals & $12.58 \pm 4.48$ & $8.99 \pm 1.78$ & 4.84 & 0.00 \\
\hline $\begin{array}{l}\text { Flexibility of the lower back and } \\
\text { hamstring muscles }\end{array}$ & $16.95 \pm 2.88$ & $16.89 \pm 1.65$ & 1.09 & 0.52 \\
\hline $\begin{array}{l}\text { ABC-PA-SSCE: Group with 3 min ABC-PA with static stretching chair exercises/ ABC-PA-DSCE } \\
\text { Groups with 3 min ABC-PA with dynamic stretching standing chair exercises. }\end{array}$ \\
\hline
\end{tabular}

FitnessGram test batteries were disclosed in the interests of ABC-PA-Sit-to-Stand in all components tested (Cooper Institute for Aerobics Research, 2017). Except for the flexibility of the low back and hamstring muscles compared to group ABC-PA-Sit-Downs. Evidence was strengthened by the Isokinetic and Exercise Science researchers. The core stability training is not generating sufficient stimulus to improve power and strength dependent performance skills, such as sprint, agility and cardinal components in conditioning programs (Sever et al. 2018). It was confirmed in this study by components of the FitnessGram test battery in the comforts of ABC-PA-sit-to-stand. It was report as a significant energetic exercise able to improve physical everyday fitness and reducing total sitting classroom time compete to ABC-PA-Sit-Downs (Figure 3). Mark et al. agreed that significant short break from sitting to standing, highly increase general fitness goals and weight loss (Mark et al. 2004). Porcari et al. (2015) proclaimed these benefits can improve functional range of motion and mobility in sports or activities for daily living (Porcari et al. 2015). Kevin et al. (2019) showed that through the potency of active exercises joined with static stretch as more optional than static stretch exercises improves the movement time of the upper extremities, body overall coordination and 
dynamic flexibility improvement. It was inspected as these routine integrated into the warm-up improved gain in max work capacity and recovery, improvements in strength, flexibility, and respiratory muscle endurance functionality (Kevin et al. 2019).

Table 3

Present the Pearson correlation post-test between Fitness Gram test and sample results (Cooper Institute for Aerobics Research, 2017)

\begin{tabular}{|c|c|c|c|}
\hline \multicolumn{2}{|l|}{ Pearson Correlation } & $\begin{array}{l}\text { ABC-PA-Sit-to- } \\
\text { Stand }\end{array}$ & $\begin{array}{l}\text { ABC-PA-Sit- } \\
\text { Downs }\end{array}$ \\
\hline Aerobic capacity & \multirow[t]{6}{*}{$\mathrm{N}=90$} & $0.84^{* *}$ & $-0.82^{* *}$ \\
\hline Body composition & & $0.54^{* *}$ & $-0.72^{* *}$ \\
\hline Muscular strength upper body & & $0.78^{* *}$ & $-0.75^{* *}$ \\
\hline Muscular strength lower body & & $0.84^{* *}$ & $-0.82^{* *}$ \\
\hline Endurance Abdominals & & $0.81^{* *}$ & $-0.84^{* *}$ \\
\hline $\begin{array}{l}\text { Flexibility of the low back and hamstring } \\
\text { muscles }\end{array}$ & & $0.87^{* *}$ & $0.86^{* *}$ \\
\hline \multicolumn{4}{|c|}{$\mathrm{P} \leq 0.05^{* *}$. Correlation is significant at the 0.01 level (2-tailed) } \\
\hline
\end{tabular}

\section{Discussion}

The primary objective of this study was analysing the effects of stretch chair exercises with and without Sit-to-Stand on potency of classroom-based physical activity intervention programs. Advised in this pilot Algerian study under two chair-based exercise modalities. It was expected to enable physical activity to be prioritised during the school day (James et al. 2011). While without a set-up into their interventions and no longer than 5 min, according to Australian teachers (Agata et al. 2018). Practices recommended by Algerian teachers through sit-downs were found as ideal classroom settings aspects of good discipline pedagogical and successful learning behaviour (Mohammed 2017). The model in this study ABC-PA-Sit-Downs combined static stretching chair exercises. The ABC-PA-Sit-to-Stand was composed of dynamic standing exercises. This study modifications were estimated in terms of frequency and intensity to test their feasibility and fidelity. Amanda et al. (2019) confirmed essential guidance to structure recommend classroom-based physical activity intervention programs. Based on independent t-test, all results are in the interests of Sit-to-Stand as potency classroom-based chair physical activity compared to ABC-PA-Sit-Downs. This study confirms sit to stand as the more energetic chair exercise able to enhance the components included in the FitnessGram test battery. 
Evidence indicated by strength and conditioning trainers claimed advantages of dynamic exercises and high-volume upper extremity plyometric activities (Nebojša and Špela 2020). Multi-joint activities request step-ups and sit-to-stand (Olaf et al. 2016) to improve body movement that results in energy expenditure, aerobic or oxygen-requiring energy systems, muscle strength, flexibility, balance, coordination, and cardiorespiratory endurance (Bania et al. 2016).

As it is interpret in this study, requested chair-based exercises energy expenditure is able to break physical classroom routine programs (Alicia and Laura 2018). The components of Fitness Gram battery tests cerfies the potency of step-ups and sit-to-stand, not Static Stretching Chair Exercises to enhances the five essential motor abilities as endurance, flexibility, coordination, strength, and speed (Feng et al. 2018). Nancy and June (2005) revealed significant amount works performance necessitated within static post-workout exercise stations. They meaningfully improve suitable strength, necessary flexibility and aerobic and anaerobic power (Mohammed 2019). Step-ups and sit-to-stand are valuable explosive movements combined with static stretch to increase recovery time. Records of this study showes the recommended combination to enhance the energy expenditure relative to demanded heart rate. by Koepp et al. (2016) documented the surpluses $20-30 \%$ of energy expenditure. Especially under sedentary behaviour in which energy expenditure is less than1.5 METS (Frank 2009). The case of ABCPA-Sit-Downs, found in this study serves to increase static flexibility and range of motion (Heneghan et al. 2017; Andreas \& Felix 2017). In this study it is recommended to include it into post-workout to speed recovery, decrease soreness and increasing muscle length (Fleck \& Kraemer 2014) especially within ABC-PA-Sit-to-Stand.

This unique employment of chair-based classroom physical activity was recognised in this study, as extended static stretching. Strength training studies reported an optimal combination that can be used before the performance to facilitate the range of motion and succeeding performance (John 2013). Strength Trainers pointed adequate warm-up session to improve muscle compliance and enhance muscle force development, in comparison to warmup that consists solely of static stretching (Bram 2016). Sciences of physical therapy through the efficacy of dynamic sitting exercises pointed that it hepls to prevent and decrease the lumbar range of movement in both back flexion and extension following a 2-hour prolonged sitting (Uraiwan et al. 2015). Farzane et al. (2018) suggested to decrease sedentary time and increase the daily energy expenditure to prevent weight gain in the long term (Farzane et al. 2018). This study recommend to implement more energetic classroom-based physical activity intervention programs. 


\section{Conclusion}

This study affirms Sit-to-Stand within the school classroom as a required exercise to structure the optional active break routine classroom programs. In this study we claimed that with an adequate intensity and frequency, it is able to improve overall fitness, tone muscle and strengthen global body posture. In the interests of ABC-PA-Sit-to-Stand was approved and mix both work resistance limb exercises, to enhance schooling-health-related fitness components compared to ABC-PA-stretch sit-downs. It is recommended in this study to prolong stretch aimed to gain flexibility, but not to boost post-work cardiorespiratory fitness energy expenditure. It is requested in classroom-based physical activity intervention program to reduce the impacts of waking behaviour characterised by an energy expenditure of $\leq 1.5$ METs.

\section{Acknowledgements}

As specialists in physical education and sport, we recommend Sit-to-Stand to be practised in classroom breaking activity programs. This study admitted one of several recommendations to raise cardiorespiratory fitness, energy expenditure and reducing the total daily chair sedentary time compared to ABC-PA-stretch sit-downs. The prolonged passive stretch should be primarily assessed after intensive break activity or at the end of active break program to gain in static flexibility, relaxation, the reduction of the client's stress level and muscle soreness.

Financial support and sponsorship. No financial support.

Conflicts of interest. There are no conflicts of interest.

\section{References}

1. AGATA, G., G. JOANNA, L.K. IDA, C. MING-KAI, R.E CHRISTOPHER, M.C.M. MAGDALENA AND B. MICHAL, 2018. The Impact of Brain Breaks Classroom-Based Physical Activities on Attitudes toward Physical Activity in Polish School Children in Third to Fifth Grade. Int J Environ Res Public Health. 15(2), 368.

Doi:https://dx.doi.org/10.3390\%2Fijerph15020368.

2. ALICIA, C.S. AND F.P.LAURA, 2018. The Impact of Physically Active Brain Breaks on College Students' Activity Levels and Perceptions. Journal of Physical Activity Research. 3(1), 60-67. DOI:10.12691/jpar-3-1-10. 
3. AMANDA, W., T. ANNA, B. HELEN \& D.H. KYLIE, 2017. A Primary School Active Break Programme (ACTI-BREAK): Study Protocol for a Pilot Cluster Randomised Controlled Trial. Trials. 18, 433. Doi:https://doi.org/10.1186/s13063-017-2163-5

4. AMANDA, W., T. ANNA, B. HELEN \& K.H., 2019. Process evaluation of a classroom active break (ACTI-BREAK) program for improving academic-related and physical activity outcomes for students in years 3 and 4. BMC Public Health. 19, 633. Doi:https://doi.org/10.1186/s12889-019-6982-z

5. ANDREAS, B.I. \& H.S. FELIX, 2017. Shoulder Instability Across the Life Span. Berlin, Germany: Springer.

6. BANIA, T.A., K.J. DODD, R.J. BAKER, H.K. GRAHAM \& N.F. TAYLOR, 2016. The effects of progressive resistance training on daily physical activity in young people with cerebral palsy: a randomised controlled trial. Disabil Rehabil. 38(7), 620-626. DOI:10.3109/09638288.2015.1055376

7. BRAM, S., 2016. Strength Training for Soccer. London: Routledge.

8. CHIN, M.K., C.R. EDGINTON AND M.S. TANG, 2012. School physical education and health: A model of best practice, integrating local context with global trends. Glob. J. Health Phys. Educ. Pedagog. 1, 251-282.

9. COOPER INSTITUTE FOR AEROBICS RESEARCH, 2017. Fitness Gram administration manual: the journey to MyHealthyZone. Champaign, IL: Human Kinetics.

10. FARZANE, S., R.M. JOSE, S. MARTA, P.O. THOMAS, K.S. VIREND, J.E. PATRICIA, AND L.J. FRANCISCO, 2018. Differences of energy expenditure while sitting versus standing: A systematic review and meta-analysis. Eur J Prev Cardiol. 25(5), 522-538. DOI:10.1177/2047487317752186

11. FENG, L., W. WEIHUA, M.A. JINGANG, S.A. RINA \& Z. GUIHUA, 2018. Different associations of sufficient and vigorous physical activity with BMI in Northwest China. Scientific Reports volume. 8(13120), 1-7. Doi:https://doi.org/10.1038/s41598-018-31227-6

12. FLECK, S.J. \& W. KRAEMER, 2014. Principles of strength and conditioning. 4E. USA: Human Kinetics.

13. FRANK, R.N., 2009. Noyes' Knee Disorders: Surgery, Rehabilitation, Clinical Outcomes E-Book. Saunders: Elsevier Health Sciences.

14. HENEGHAN, R.N, G. BAKER, K. THOMAS, F. DEBORAH AND R. ALISON, 2017. What is the effect of prolonged sitting and physical activity on thoracic spine mobility? An observational study of young adults in a UK university setting. Rehabilitation medicine. 8(5), e019371. Doi:http://dx.doi.org/10.1136/bmjopen-2017-019371 
15. IZET, M., 2018. Public Health Aspects of Global Population Health and Well-being in the 21st Century Regarding Determinants of Health. Int J Prev Med. 9(1),4. DOI: 10.4103/ijpvm.IJPVM_476_17

16. JAMES, T.C., E.P. ROSS, M.L. RONALD AND B.L. CAROL, 2011. Textbook of pediatric rheumatology. Philadelphia, PA: Saunders.

17. JOHN, S., 2013. The Complete Guide to Sports Training. London: Bloomsbury Sport.

18. KEVIN, C.C., Y. SHENG-CHE, J. MILAGROS AND M.L. MICHELLE, 2019. Orthotics and Prosthetics in Rehabilitation E-Book. Elsevier Health Sciences.

19. KOEPP, G.A., G.K. MOORE \& J.A. LEVINE, 2016. Chair-based fidgeting and energy expenditure BMJ Open Sport \& Exercise Medicine. 2(1):e000152. doi: 10.1136/bmjsem2016-000152

20. KRAUSE, J.M. \& E.A. BENAVIDEZ, 2014. Potential influences of exergaming on selfefficacy for physical activity and sport. J. Phys. Educ. Recreat. Dance. 85, 15-20. DOI:10.1080/07303084.2014.884428

21. MARK, C. \& T. SHARON, 2004. Revise in a month VCE physical education. Glebe, N.S.W: Pascal Press.

22. MOHAMMED, Z., 2017. Impact of Prolonged Periods Classroom Settings in Intraabdominal fat area and its Consequence on Posture/Balance Control among Algerian Childhood College Preparatory School. International Journal of Applied Exercise Physiology. 6(2), 20-26. Doi:https://doi.org/10.22631/ijaep.v6i2.88

23. MOHAMMED, Z., 2018. Leaving school and its outcomes on adolescents' behavioral goals and change cognitions to times physically and socially inactive. Arab Journal of Nutrition and Exercise (AJNE). 1-17. DOI:10.18502/ajne.v3i41.1691

24. MOHAMMED, Z., 2019. Dance-based body-movement as kinesthetic therapy to reduce the impact of Prolonged Periods Classroom Settings Algerian Primary School. World News of Natural Sciences (WNOFNS). 23, 56-68.

25. MOHAMMED, Z., A. NOUREDDINE AND F.A. BEN, 2017. Abdominal Obesity and their association with Total Body: Fat Distribution and Composition. Case of Algerian Teenager Male high school students. Physical education of students. 21(3), 146-151. Doi:https://doi.org/10.15561/20755279.2017.0308

26. NANCY, J.H. \& H. UNE, 2005. Multiple Sclerosis: A Self-Care Guide to Wellness, Second Edition. New York: Paralyzed Veterans of America. 
27. NEBOJŠSA, T., AND B. ŠPELA, 2020. Effects of Neuromuscular Training on Motor Competence and Physical Performance in Young Female Volleyball Players. Int. J. Environ. Res. Public Health. 17(5), 1755. DOI: https://doi.org/10.3390/ijerph17051755

28. OLAF, V., D.P. MARK, C.J. ASTRID AND A.H. EDWARD, 2016. Exercise and Physical Activity Recommendations for People with Cerebral Palsy. Dev Med Child Neurol. 58(8), 798-808. Doi:https://dx.doi.org/10.1111\%2Fdmen.13053

29. Porcari, P. J., Cedric, X.B., Fabio, C. (2015). Exercise Physiology. Philadelphia, PA: F.A. Davis Company.

30. SEVER, O. \& E. ZORBA, 2018. Comparison of effect of static and dynamic core exercises on speed and agility performance in soccer players. Isokinetics and Exercise Science. 26(1), 29-36. DOI: $10.3233 /$ IES-171120

31. URAIWAN, C., J. UNTHIKA, C. SUNISA, P. RUNGTHIP, D. WANIDA AND Y. JUNICHIRO, 2015. Immediate effects of dynamic sitting exercise on the lower back mobility of sedentary young adults. $J$ Phys Ther Sci. 27(11), 3359-3363. DOI:10.1589/jpts.27.3359

32. VIRGINIA, A.A., A. SORIANO-MALDONADO, F. BUITRAGO, F. FÉLIX-REDONDO AND D. FERNÁNDEZ-BERGÉS, 2016. The Role of Sex and Domestic Physical Activity on the Metabolically Healthy and Unhealthy Obesity. The HERMEX Study. Rev Esp Cardiol. 69(10), 983-6. Doi:10.1016/j.rec.2016.04.050 